\title{
$\mathrm{PV}$ 시스템이 적용된 농어촌 주택 표준모델의 에너지 경제성 분석 \\ 이찬규 ${ }^{1}$, 김우태 ${ }^{2 *}$ \\ ${ }^{1}$ 공주대학교 대학원 기계공학과, ${ }^{2}$ 공주대학교 기계자동차공학부
}

\section{Energy Economic Analysis of Standard Rural House Model with PV System}

\author{
Chan Kyu Lee ${ }^{1}$ and Woo Tae Kim ${ }^{2^{*}}$ \\ ${ }^{1}$ Department of Mechanical Engineering, Kongju National University \\ ${ }^{2}$ Department of Mechanical and Automotive Engineering, Kongju National University
}

\begin{abstract}
요 약 국가 에너지 소비의 $25 \%$ 를 차지하는 건물에너지의 저감과 귀농인구의 증가에 따른 저에너지 친환경 주택 모델의 수요 충족을 위해 EnergyPlus를 사용하여 PV 시스템이 적용된 농어촌 주택 표준모델의 건물에너지요구량을 기반으로 경제성 분석을 하였다. 2 가지 타입의 $\mathrm{PV}$ 시스템이 적용되었고 발전된 전력을 건물의 냉방기기와 전기기기, 그리고 난방기기에 사용하였다. 계산에 사용된 주택의 연간 건물에너지요구량은 난방이 냉방에 비해 7 배 크게 나타났 다. Case1과 Case2로 나누어 PV 시스템의 경제성분석을 실시한 결과, Case1은 냉난방 및 전기기기에 발전된 전력을 사용하고 판매하는 것이, $\mathrm{Case2}$ 는 냉방과 전기기기에만 전력을 사용하고 전량 판매하는 것이 경제적으로 유리한 것으 로 판단된다. 하지만, 향후 전력 판매가격과 가스가격이 변동되면 결과는 달라질 수 있다. 초기투자비용은 Case1이 약 13 년, Case2는 약 11년이 지나면 회수되는 것으로 나타났다. Case2가 초기설치비용이 비싸지만 회수기간이 지나면 Case1보 다 약 3 배 더 많은 이익을 얻을 수 있어 수명연한인 25 년 이상 사용 시 경제성 측면에서 유리할 것으로 판단된다.
\end{abstract}

\begin{abstract}
The energy economic analysis of the standard rural house model with PV system was performed based on annual energy demand calculation using the EnergyPlus to contribute in reducing building energy which occupies $25 \%$ of national energy consumption and in developing a low-energy \& eco-friendly house model. Two types of PV system installation was considered to cover electricity demand for cooling, electric, and heating devices. For the selected house model, heating energy demand is 7 times higher than cooling energy demand. For the Case1, it is favorable to use electricity from PV system for cooling and electric devices and to sell surplus electricity. For the Case2, it is favorable to use electricity from PV system for cooling, electricity and heating devices and to sell surplus electricity. Considering the installation cost of PV system and heat pump air conditioning system, the break-even point of Case1 and Case2 are about 13 and 11 years respectively. Although the installation cost of Case2 is more expensive, Case2 provides three times more profit than Case1 after the break-even point. Because the expected average life time of the selected PV system is 25 years, Case2 is more favorable option for the given standard rural house model.
\end{abstract}

Key Words : Photovoltaic system, EnergyPlus, Building information modeling, Standard rural house model, Economic analysis

\section{1. 서론}

웰빙생활과 식품안전에 대한 관심이 증가하면서 귀농.
귀촌 인구가 늘어남에 따라 정부에서는 2009년 4월 귀농. 귀촌 종합대책을 발표하였다[1]. 또한 한국농어촌공사에 서는 농어촌 주택설계에 드는 시간적, 경제적 부담을 덜

${ }^{*}$ Corresponding Author : Woo Tae Kim(Kongju National Univ.)

Tel: +82-10-2877-5362 email: wtkim@kongju.ac.kr

Received January 18, 2013 Revised April 10, 2013 Accepted April 11, 2013 
어주기 위해 설계도서를 미리 작성하여 두고 건축하고자 하는 국민들의 취향에 따라 이를 선택적으로 이용할 수 있도록 공고하고 있다[2].

에너지 해외의존도가 약 $97 \%$ 에 달하는 우리나라는 안 정적인 에너지 수급과 2013년 온실가스 감축 의무 대상 국으로 지정될 경우를 대비하기 위해 에너지 절감에 노 력해야한다. 국가 에너지 소비량의 $25 \%$ 를 차지하는 건물 에너지 소비를 줄이기 위해 다방면의 연구가 진행 중이 다.[3,4,5] Yoon et al.은 공동주택에 적용된 PV(photovoltaic) 시스템의 최적 설치 면적과 배치 형태에 따른 발전량을 분석하였으며[3] Lee et al.은 창호의 종류와 건축물의 방 향에 따른 건물에너지요구량 변화를 분석했다[4]. Chin et al.은 공동주택의 발코니에 PV 시스템을 적용하고 PV 패 널의 설치경사각에 따른 시스템의 성능을 평가했다[5]. 또한 신재생에너지 설치 의무화 사업의 시행으로 신재생 에너지 설비 도입비율이 증가하고 있다. 국내에도 이미 각종 태양광 보급사업을 통해 많은 건물에 PV 시스템이 적용되고 있으며 태양광 시장은 연간 $68 \%$ 성장하고 있 다. 최근에는 태양광 발전 기술요소들의 도입을 통하여 건물 에너지 소비를 줄이기 위한 건축 계획적 방법이 활 발하게 연구되고 있다[6].

PV 시스템의 효율은 시스템의 구조나 형태, 건물의 형 태, 방향, 지역기후특성, 모듈의 설치각도 등의 영향을 많 이 받기 때문에 시뮬레이션에 의한 분석은 다양한 엔지 니어링 데이터 및 기상자료를 기반으로 한 해석이 필수 이다. 현재 일반적으로 활용되는 PV 시스템 전용 분석 프로그램은 PV Sola, PVSYST, Solar-pro 등이 있으며 건 물에너지 해석프로그램 내에서 PV 시스템의 해석을 지 원하는 프로그램은 EnergyPlus, TRNSYS, Energy-10 등 이 있다[7].

본 연구에서는 귀농인들이 사용할 저에너지 친환경 주 택인 농어촌 주택 표준모델의 연간 건물에너지요구량을 EnergyPlus를 사용하여 분석하였다. 주택의 지붕에 설치 된 PV 시스템의 발전량을 계산하고 연간 에너지요구량 충당에 따른 비용절감과 초기 투자비를 고려한 경제성 분석을 실시하여 농어촌 주택 표준모델에 PV 시스템 설 치 시 참고할 수 있는 기초자료를 제시하였다.

\section{2. 연구방법}

\section{1 농어촌 주택 표준모델}

농어촌 주택 표준설계도서는 1995년부터 2010년까지 76 개 유형이 발표되었으며 최근 농어촌 라이프 스타일을
반영하는 2010년 평면도에서 도면을 추출하고, 형태적으 로는 단층형 모델 중 Fig. 1의 모델을 선정하였다. Fig. 1 은 농림-10-33-다 모델로 총 면적은 $110.4 \mathrm{~m}^{2}$ 이다. 거주 자가 주로 생활하는 안방, 방 3 개, 거실, 주방, 공용면적 을 하나의 난방존으로 설정하고 공기조화 조건을 적용하 였다. 난방존의 면적은 $73.9 \mathrm{~m}^{2}$ 이다[8].

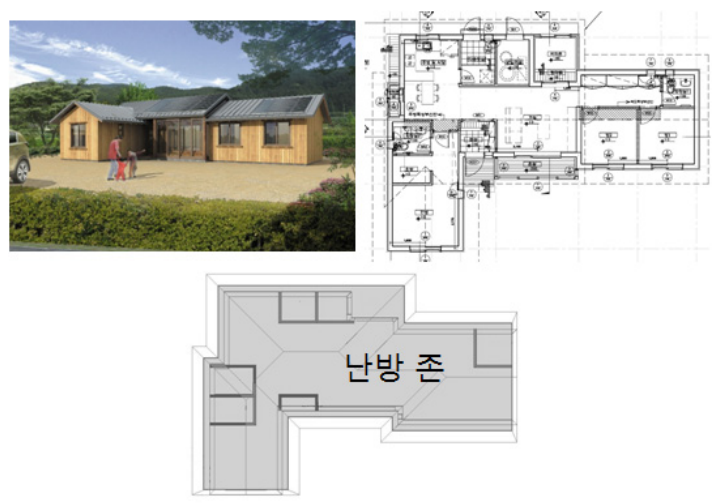

[Fig. 1] Standard rural house model Nonglim-10-33-Da

\subsection{EnergyPlus}

본 논문의 계산에 사용된 EnergyPlus는 미국 에너지성 (U.S. Department Of Energy)에서 개발한 에너지 시뮬레 이션 프로그램으로 사용자가 입력한 건물의 특성에 따라 건물의 냉난방부하를 계산한다. 또한 PV 시스템, 지열히 트펌프, 태양열 집광기 등의 신재생에너지를 건물에 설치 한 경우 에너지 발생량을 계산하여 건물에너지해석에 고 려할 수 있다[9]. 건물외부의 기후조건은 ASHRAE (American society of heating, refrigerating and air-conditioning engineers)의 기상데이터를 이용하여 간 편하고 정확하게 에너지 계산을 수행할 수 있다[10].

\section{3 계산 조건}

계산에 적용한 조건을 Table 1 에 나타내었다. EnergyPlus에서는 공주대학교 천안공과대학이 위치한 천 안의 EPW(EnergyPlus weather) 기후데이터를 제공하지 않으므로 중부지방인 인천의 날씨 데이터를 사용하였다. 실내의 기준온도를 에너지관리공단에서 권장하는 온도인 난방 $20^{\circ} \mathrm{C}$ 와 냉방 $26^{\circ} \mathrm{C}$ 로[11] 설정하였다. 실내발열조건 은 국토해양부와 에너지관리공단이 효과적인 에너지관리 를 위해 제정한 건축물 에너지 효율 등급인증 제도 운영 규정을 사용하여 설정하였다[12]. 
[Table 1] Simulation conditions

\begin{tabular}{|c|c|}
\hline Weather Data & $\begin{array}{c}\text { Inchoen } \\
\text { 2002 EPW Data }\end{array}$ \\
\hline Temperature Set-point & $\begin{array}{c}\text { Heating } 20^{\circ} \mathrm{C} \\
\text { Cooling } 26^{\circ} \mathrm{C}\end{array}$ \\
\hline Resident Schedule & $\begin{array}{l}\text { Weekdays } 18: 00 \sim 08: 00 \\
\text { Weekend 00:00 24:00 }\end{array}$ \\
\hline Glazing & $\begin{array}{c}\text { Single Glass } \\
\text { Clear Glass } 6 \mathrm{~mm}\end{array}$ \\
\hline Infiltration & $0.5 \mathrm{ACH}$ \\
\hline Exclusive Using Area & $110.4 \mathrm{~m}^{2}$ \\
\hline Electric Heat Gain & $3.50 \mathrm{~W} / \mathrm{m}^{2}$ \\
\hline Resident & $3.90 \mathrm{person}$ \\
\hline Human Heat Gain & $149 \mathrm{~W}$ \\
\hline
\end{tabular}

[Table 2] Properties of construction materials

\begin{tabular}{|c|c|c|c|}
\hline & Material & $\begin{array}{c}\text { Conductivity } \\
\left(\mathrm{W} / \mathrm{m}^{2} \cdot \mathrm{K}\right)\end{array}$ & $\begin{array}{c}\text { Thickness } \\
\text { (m) }\end{array}$ \\
\hline \multirow{2}{*}{$\begin{array}{c}\text { Outside } \\
\text { Wall }\end{array}$} & $\begin{array}{c}\text { Weather } \\
\text { Board }\end{array}$ & 0.14 & 0.100 \\
\hline & Wood-Pine & 0.17 & 0.150 \\
\hline \multirow{3}{*}{$\begin{array}{l}\text { Inside } \\
\text { Wall }\end{array}$} & Plaster & 0.16 & 0.010 \\
\hline & Wood-Pine & 0.17 & 0.100 \\
\hline & Plaster & 0.16 & 0.010 \\
\hline \multirow{3}{*}{ Roof } & Clay Tile & 1.00 & 0.025 \\
\hline & $\begin{array}{c}\text { MW Stone } \\
\text { Wool }\end{array}$ & 0.04 & 0.095 \\
\hline & Roofing Felt & 0.19 & 0.005 \\
\hline \multirow{3}{*}{ Floor } & $\begin{array}{c}\text { External } \\
\text { Rendering }\end{array}$ & 0.50 & 0.025 \\
\hline & $\begin{array}{c}\text { MW Stone } \\
\text { Wool }\end{array}$ & 0.04 & 0.075 \\
\hline & $\begin{array}{c}\text { Timber } \\
\text { Flooring }\end{array}$ & 0.14 & 0.005 \\
\hline Glazing & $\begin{array}{c}\text { PPG } \\
\text { Clear Glass }\end{array}$ & 1.00 & 0.006 \\
\hline
\end{tabular}

[Table 3] Primary energy scaling factor for different energy sources

\begin{tabular}{|c|c|}
\hline & Primary Energy Scaling Factor \\
\hline Fossil Fuel & 1.1 \\
\hline Electricity & 2.75 \\
\hline District Heating & 0.614 \\
\hline District Cooling & 0.937 \\
\hline
\end{tabular}

발열스케쥴은 전기기기의 경우 하루 중 3 시간 정도로 가정하였으며 재실자 발열은 농어촌 생활특성을 감안하 여 주중 18:00 08:00, 주말 24시간으로 설정하였다. 건 물에 적용된 창호는 $\mathrm{PPG}$ 사의 $6 \mathrm{~mm}$ 단일창호를 채택하 였고 침기량은 $0.5 \mathrm{ACH}$ (air change per hour)를 적용하였 다. 모든 설정은 재실자가 주로 거주하는 난방 존에만 설 정하였다. 또한 Table 2 의 외벽조건을 적용하여 연간 에 너지요구량을 분석하였다.

\section{3. 결과 및 토의}

\section{1 건물에너지요구량 분석}

농림-10-33-다 모델의 설계도면을 기준으로 제작한 형 상모델에 계산조건을 적용하고 EnergyPlus를 사용하여 건물에너지요구량을 계산하였다. 연간 난방에너지요구량 은 약 $21.81 \mathrm{MWh}$, 냉방에너지요구량은 약 $3.18 \mathrm{MWh}$ 로 난방에너지요구량이 냉방에너지요구량보다 큰 것으로 나 타났다. 또한, 전기기기의 연간 발열량은 약 $1.08 \mathrm{MWh}$ 로 나타났다. 건축물 에너지 효율등급 인증제도에서 신축 공 동주택과 업무용 건축물의 등급을 연간단위면적당 1 차 에너지 소요량 $\left(\mathrm{kWh} / \mathrm{m}^{2} \cdot \mathrm{yr}\right)$ 을 기준으로 나눈다. 1차 에너 지 소요량은 에너지 요구량과 에너지 요구량을 공급하기 위해 사용하는 냉난방기기의 에너지 손실량을 고려한 값 인 에너지 소요량에 Table 3 의 1차적 에너지인 화석연료 량으로 환산하는 계수를 곱하여 구한다. $\mathrm{kWh} / \mathrm{m}^{2}$ 단위에 서 300 미만은 1 등급, 300 이상 350 미만은 2 등급, 350 이상 400 미만은 3 등급, 400 이상 450 미만은 4 등급, 그 리고 450 이상 500 미만은 5 등급이다. 본 연구에서 주택 표준모델의 냉방에는 국내에 시판되는 COP 3.72 의 상용 냉방기를 적용하고 난방의 경우는 효율 $88 \%$ 의 가스보일 러를 사용한다고 가정하였다. 건물효율등급 산정을 위해 1 차 에너지 환산계수를 적용하여 계산한 결과 난방 1 차 에너지 소요량은 약 $27.26 \mathrm{MWh}$, 냉방 1차 에너지 소요 량은 약 $2.35 \mathrm{MWh}$, 전기기기의 1 차 에너지 소요량은 약 $2.97 \mathrm{MWh}$ 이다. 총 건물 1차 에너지 소요량은 약 32.58 $\mathrm{MWh}$ 이며 단위면적당 에너지소요량은 약 295.91 $\mathrm{kWh} / \mathrm{m}^{2}$ 로 1 등급 건물에 해당한다. $\mathrm{PV}$ 발전량으로 냉난 방기와 전기기기의 전기소요량을 충당하게 되면 단위면 적당 에너지소요량은 더 감소한다.

\section{2 주택 표준모델에 적용된 PV 시스템의 발 전량 분석}

표준 주택모델에 PV 시스템을 적용하고 2가지 적용형 태에 따른 발전량 차이를 분석하였다. PV 패널의 적용위 치는 Fig. 2 와 같이 지붕의 남쪽면에 설치한 PV1과 지붕 의 북쪽면에 설치한 PV2 두 개의 영역으로 구성되어있으 며 모든 시스템은 남향으로 설치하였다. 본 계산에서는 PV 패널로 인해 지붕의 열관류율이 변하지 않는다고 가 정하였고 계산에 적용된 $\mathrm{PV}$ 패널의 특성은 Table 4[13] 와 같다. 모든 패널은 Park and Seo의 연구결과를 토대로 [14] 최적의 효율을 얻기 위해 인천지역 최적경사각 $37^{\circ}$ 로 설치하였다. 


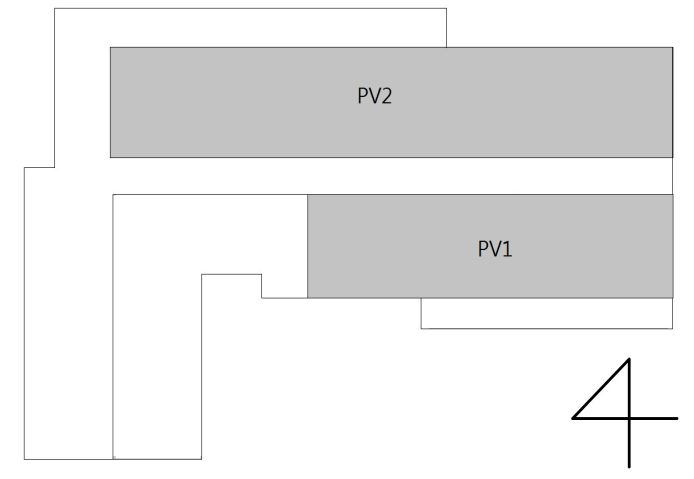

[Fig. 2] Roof section for the PV system installation

[Table 4] Properties of a PV panel

\begin{tabular}{|c|c|c|}
\hline & Properties & Value \\
\hline \multirow{8}{*}{$\begin{array}{l}\text { LG255S1C } \\
\text { PV Module }\end{array}$} & Maximum Power & $255 \mathrm{~W}$ \\
\hline & $\begin{array}{l}\text { Current at Maximum } \\
\text { Power Point }\end{array}$ & $8.5 \mathrm{~A}$ \\
\hline & $\begin{array}{c}\text { Voltage at Maximum } \\
\text { Power Point }\end{array}$ & $30 \mathrm{~V}$ \\
\hline & Short Circuit Current & $8.85 \mathrm{~A}$ \\
\hline & Open Circuit Voltage & $37.2 \mathrm{~V}$ \\
\hline & $\begin{array}{c}\text { Maximum System } \\
\text { Voltage }\end{array}$ & $1000 \mathrm{~V}$ \\
\hline & Average PV Efficiency & $15.84 \%$ \\
\hline & PV Panel Size & $1.46 \mathrm{~m}^{2}$ \\
\hline \multirow{2}{*}{ Inverter } & $\begin{array}{l}\text { Average Inverter } \\
\text { Efficiency }\end{array}$ & $90 \%$ \\
\hline & $\begin{array}{l}\text { Maximum Inverter } \\
\text { Capacity }\end{array}$ & $10 \mathrm{~kW}$ \\
\hline
\end{tabular}

[Table 5] Annual electricity generation and electricity generation per unit exclusive using area for the PV system

\begin{tabular}{|c|c|c|}
\hline & $\begin{array}{c}\text { Electricity } \\
\text { Generation } \\
(\mathrm{MWh})\end{array}$ & $\begin{array}{c}\text { Electricity } \\
\text { Generation per Unit } \\
\text { Exclusive Using Area } \\
\left(\mathrm{kWh} / \mathrm{m}^{2}\right)\end{array}$ \\
\hline $\begin{array}{c}\text { Case1 } \\
\text { (PV1) }\end{array}$ & 6.69 & 190.84 \\
\hline $\begin{array}{c}\text { Case2 } \\
\text { (PV1+PV2) }\end{array}$ & 17.87 & 191.22 \\
\hline
\end{tabular}

$\mathrm{PV} 1$ 을 적용한 Case1과 PV1, 2를 모두 적용한 Case2로 나누어 계산하였다. PV1에는 PV 패널24개, PV2에는 40 개를 적용하였다. PV1의 패널은 6개씩 직렬로 연결해서 만들어진 4개의 그룹을 병렬로 연결해 어레이를 구성하 였고 PV2는 10개씩 직렬로 연결해서 만들어진 4개의 그 룹을 병렬로 연결하였다.

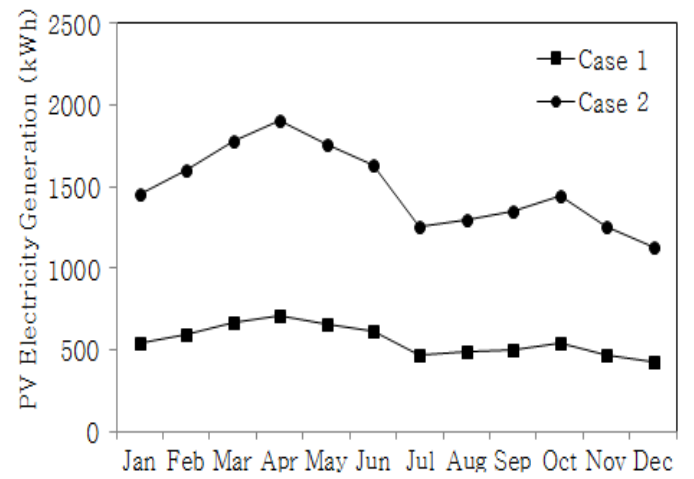

[Fig. 3] Monthly PV electricity generation

어레이는 인버터와 직산 결과는 Table 5 와 같다. Fig. 3 은 월별 PV 시스템의 전기발전량을 나타낸 결과이다. 두 Case 모두 3, 4, 5월의 발전량이 타 월에 비해 많았다. 이는 수직입 사광량이 $3,4,5$ 월에 크기 때문으로 사료된다.

\section{3 주택 표준모델에 적용된 PV 시스템의 경 제성 분석}

Fig. 3의 월별 PV 발전량은 EnergyPlus를 통해 계산한 결과를 나타낸 것으로 실시간으로 전기부하에 대응한다. Table 6은 냉방기기와 전기기기에 사용되는 전력에 대한 전력구매 비용을 나타낸다. 냉방기기에 사용되는 전력량 은 냉방에너지요구량에 냉방장치의 $\mathrm{COP}$ 를 나누어 구할 수 있다. 냉방장치와 전기기기에 사용되는 전력을 2012 년 현재 전력요금표를 기준으로 한국전력에서 구매할 경 우 연간 약 217 천원의 비용이 발생한다. 또한 난방요구량 을 가스보일러를 사용하여 전부 충당할 경우 국내 보일 러의 평균 효율 $88 \%$ 를 기준으로 경기도 난방가스요금 20 원 $/ \mathrm{MJ}$ 을 적용하여 계산한 결과 Table 7 의 값을 얻었으 며 연간 1,783 천원이 발생한다. PV 시스템을 설치하는 경우 국가 보급보조사업의 보조금을 받기위해서는 규정 에 따라 $5 \mathrm{~kW}$ 미만의 시스템을 설치해야한다. 이 경우 한전과 상계처리하기 때문에 잉여전력이 생겨도 한전에 판매할 수 없다. 반면 신재생에너지의무할당제에 의해 자 부담 $100 \%$ 로 설치하는 경우에는 한국전력에 350 원 $/ \mathrm{kWh}$ 에 판매할 수 있다. 본 논문에 적용된 PV 시스템의 경우 설치규모가 Case1은 $6.12 \mathrm{~kW}$, Case2는 $16.32 \mathrm{~kW}$ 로 보조 금은 적용할 수 없으며 전력은 판매할 수 있다. PV 시스 템의 전기발전량으로 냉방과 전기기기의 전력요구량을 충당하고 잉여전력을 전량 판매하는 경우와 추가적으로 난방에도 사용한 뒤 남는 전력을 판매하는 경우 두 가지 에 대해 경제성 분석을 실시하였다. 
[Table 6] Monthly cooling, heating and electric equipment energy demand and electricity cost

\begin{tabular}{|c|c|c|c|}
\hline & $\begin{array}{c}\text { Electricity } \\
\text { Demand for } \\
\text { Cooling } \\
\text { Device } \\
(\text { MWh })\end{array}$ & $\begin{array}{c}\text { Electricity } \\
\text { Demand for } \\
\text { Electric } \\
\text { Equipment } \\
(\text { MWh })\end{array}$ & $\begin{array}{c}\text { Electricity } \\
\text { Cost } \\
(\times 1000 \\
\text { KRW })\end{array}$ \\
\hline Jan & 0.00 & 0.09 & 6 \\
\hline Feb & 0.00 & 0.09 & 6 \\
\hline Mar & 0.00 & 0.09 & 6 \\
\hline Apr & 0.02 & 0.09 & 9 \\
\hline May & 0.07 & 0.09 & 16 \\
\hline Jun & 0.16 & 0.09 & 31 \\
\hline Jul & 0.20 & 0.09 & 41 \\
\hline Aug & 0.25 & 0.09 & 56 \\
\hline Sep & 0.12 & 0.09 & 24 \\
\hline Oct & 0.03 & 0.09 & 10 \\
\hline Nov & 0.00 & 0.09 & 6 \\
\hline Dec & 0.00 & 0.09 & 6 \\
\hline Total & 0.85 & 1.08 & 217 \\
\hline
\end{tabular}

[Table 7] Heating energy demand divided by gas boiler efficiency and gas cost

\begin{tabular}{|c|c|c|}
\hline & $\begin{array}{c}\text { Heating Energy } \\
\text { Demand / Gas } \\
\text { Boiler Efficiency } \\
(\text { MWh })\end{array}$ & $\begin{array}{c}\text { Gas Cost } \\
(\times 1000 \text { KRW })\end{array}$ \\
\hline Jan & 5.98 & 430 \\
\hline Feb & 4.57 & 329 \\
\hline Mar & 3.32 & 239 \\
\hline Apr & 1.51 & 108 \\
\hline May & 0.45 & 32 \\
\hline Jun & 0.02 & 2 \\
\hline Jul & 0.00 & 0 \\
\hline Aug & 0.00 & 0 \\
\hline Sep & 0.08 & 6 \\
\hline Oct & 1.00 & 72 \\
\hline Nov & 2.80 & 201 \\
\hline Dec & 5.06 & 364 \\
\hline Total & 24.79 & 1783 \\
\hline
\end{tabular}

발전된 전기를 난방에 사용할 경우 난방은 COP 3.98 의 히트펌프를 사용하며 부족한 난방요구량은 가스보일 러를 사용해 충당한다고 가정하였다. Table 8 에서 Case1 의 경우 PV 발전량에서 냉방 및 전기기기 사용을 제한 잉여전력을 전부 판매하면 1,666 천원의 이익이 발생하지 만 난방비용과 상쇄되어 총 에너지비용이 119 천원 발생 한다. 추가로 잉여전력을 난방부하에 공급하여 가스사용 량까지 줄이면 Table 9와 같은 결과를 얻는다. 4월부터 10 월에는 냉방, 전기기기, 난방을 충당하고도 전력이 남 아서 한전에 판매하여 610 천원의 수익이 났고 가스요금
831 천원이 발생하여 결과적으로 총 190 천원의 비용이 발 생했다.

[Table 8] Case1 total energy cost when the electricity from PV system was used for cooling and electric devices

\begin{tabular}{|c|c|c|c|c|c|}
\hline & $\begin{array}{c}\text { EGPV } \\
(\mathrm{MWh})\end{array}$ & $\begin{array}{c}\text { ESPV } \\
(\mathrm{MWh})\end{array}$ & $\begin{array}{c}\text { Electricity } \\
\text { Sales } \\
(\times 1000 \\
\text { KRW })\end{array}$ & $\begin{array}{c}\text { Gas Cost } \\
(\times 1000 \\
\text { KRW })\end{array}$ & $\begin{array}{c}\text { Total } \\
\text { Energy } \\
\text { Cost } \\
(\times 1000 \\
\text { KRW })\end{array}$ \\
\hline Jan & 0.54 & 0.45 & 159 & 430 & 272 \\
\hline Feb & 0.60 & 0.51 & 178 & 329 & 152 \\
\hline Mar & 0.67 & 0.58 & 201 & 239 & 37 \\
\hline Apr & 0.71 & 0.60 & 210 & 108 & -102 \\
\hline May & 0.66 & 0.49 & 173 & 32 & -141 \\
\hline Jun & 0.61 & 0.37 & 129 & 2 & -127 \\
\hline Jul & 0.47 & 0.18 & 62 & 0 & -62 \\
\hline Aug & 0.49 & 0.15 & 53 & 0 & -53 \\
\hline Sep & 0.51 & 0.30 & 104 & 6 & -98 \\
\hline Oct & 0.54 & 0.42 & 147 & 72 & -75 \\
\hline Nov & 0.47 & 0.38 & 134 & 201 & 68 \\
\hline Dec & 0.42 & 0.33 & 116 & 364 & 248 \\
\hline Tot & 6.69 & 4.76 & 1666 & 1783 & 119 \\
\hline
\end{tabular}

(EGPV: Electricity Generation from PV system ESPV: Electricity Surplus from PV system = EGPV minus electricity demand for cooling and electric devices)

[Table 9] Case 1 total energy cost when the electricity from PV system was used for cooling, electric, and heating devices

\begin{tabular}{|c|c|c|c|c|c|}
\hline & $\begin{array}{c}\text { ESPV2 } \\
(\mathrm{MWh})\end{array}$ & $\begin{array}{c}\text { Electricity } \\
\text { Sales } \\
(\times 1000 \\
\text { KRW })\end{array}$ & $\begin{array}{c}\text { AHED } \\
(\mathrm{MWh})\end{array}$ & $\begin{array}{c}\text { Gas } \\
\text { Cost } \\
(\times 1000 \\
\text { KRW })\end{array}$ & $\begin{array}{c}\text { Total } \\
\text { Energy } \\
\text { Cost } \\
(\times 1000 \\
\text { KRW })\end{array}$ \\
\hline Jan & 0 & 0 & 0.87 & 283 & 283 \\
\hline Feb & 0 & 0 & 0.50 & 164 & 164 \\
\hline Mar & 0 & 0 & 0.16 & 51 & 51 \\
\hline Apr & 0.27 & 94 & 0 & 0 & -94 \\
\hline May & 0.40 & 138 & 0 & 0 & -138 \\
\hline Jun & 0.36 & 127 & 0 & 0 & -127 \\
\hline Jul & 0.18 & 62 & 0 & 0 & -62 \\
\hline Aug & 0.15 & 53 & 0 & 0 & -53 \\
\hline Sep & 0.28 & 98 & 0 & 0 & -98 \\
\hline Oct & 0.20 & 69 & 0 & 0 & -69 \\
\hline Nov & 0 & 0 & 0.24 & 77 & 77 \\
\hline Dec & 0 & 0 & 0.79 & 256 & 256 \\
\hline Tot & 1.74 & 610 & 2.55 & 831 & 190 \\
\hline
\end{tabular}

(AHED: Actual Heating Energy Demand $=$ Heating Energy Demand / Gas Boiler Efficiency

ESPV2: EGPV minus electricity demand for heating, cooling and electric devices) 
$\mathrm{PV}$ 시스템이 적용된 농어촌 주택 표준모델의 에너지 경제성 분석

[Table 10] Case2 total energy cost when the electricity from PV system was used for cooling and electric devices

\begin{tabular}{|c|c|c|c|c|c|}
\hline & $\begin{array}{c}\text { EGPV } \\
(\mathrm{MWh})\end{array}$ & $\begin{array}{c}\text { ESPV } \\
(\mathrm{MWh})\end{array}$ & $\begin{array}{c}\text { Electricity } \\
\text { Sales } \\
(\times 1000 \\
\text { KRW })\end{array}$ & $\begin{array}{c}\text { Gas Cost } \\
(\times 1000 \\
\text { KRW })\end{array}$ & $\begin{array}{c}\text { Total } \\
\text { Energy } \\
\text { Cost } \\
(\times 1000 \\
\text { KRW })\end{array}$ \\
\hline Jan & 1.45 & 1.36 & 477 & 430 & -47 \\
\hline Feb & 1.60 & 1.51 & 528 & 329 & -198 \\
\hline Mar & 1.78 & 1.69 & 592 & 239 & -353 \\
\hline Apr & 1.91 & 1.79 & 628 & 108 & -520 \\
\hline May & 1.76 & 1.60 & 558 & 32 & -526 \\
\hline Jun & 1.63 & 1.39 & 487 & 2 & -485 \\
\hline Jul & 1.26 & 0.97 & 338 & 0 & -338 \\
\hline Aug & 1.30 & 0.96 & 338 & 0 & -338 \\
\hline Sep & 1.35 & 1.14 & 400 & 6 & -394 \\
\hline Oct & 1.44 & 1.32 & 462 & 72 & -390 \\
\hline Nov & 1.26 & 1.17 & 409 & 201 & -207 \\
\hline Dec & 1.13 & 1.04 & 364 & 364 & 0 \\
\hline Tot & 17.87 & 15.94 & 5581 & 1783 & -3796 \\
\hline
\end{tabular}

[Table 11] Case 2 total energy cost when the electricity from PV system was used for cooling, electric, and heating devices

\begin{tabular}{|c|c|c|c|c|c|}
\hline & $\begin{array}{c}\text { ESPV2 } \\
(\text { MWh })\end{array}$ & $\begin{array}{c}\text { Electricity } \\
\text { Sales } \\
(\times 1000 \\
\text { KRW })\end{array}$ & $\begin{array}{c}\text { AHED } \\
(\text { MWh })\end{array}$ & $\begin{array}{c}\text { Gas } \\
\text { Cost } \\
(\times 1000 \\
\text { KRW })\end{array}$ & $\begin{array}{c}\text { Total } \\
\text { Energy } \\
\text { Cost } \\
(\times 1000 \\
\text { KRW })\end{array}$ \\
\hline Jan & 0 & 15 & 0 & 0 & -15 \\
\hline Feb & 0.36 & 174 & 0 & 0 & -174 \\
\hline Mar & 0.86 & 335 & 0 & 0 & -335 \\
\hline Apr & 1.42 & 511 & 0 & 0 & -511 \\
\hline May & 1.48 & 524 & 0 & 0 & -524 \\
\hline Jun & 1.38 & 485 & 0 & 0 & -485 \\
\hline Jul & 0.97 & 338 & 0 & 0 & -338 \\
\hline Aug & 0.96 & 338 & 0 & 0 & -338 \\
\hline Sep & 1.12 & 393 & 0 & 0 & -393 \\
\hline Oct & 1.07 & 385 & 0 & 0 & -385 \\
\hline Nov & 0.46 & 192 & 0 & 0 & -192 \\
\hline Dec & 0 & 0 & 0.08 & 26 & 26 \\
\hline Tot & 10.08 & 3690 & 0.08 & 26 & -3664 \\
\hline
\end{tabular}

Case2는 PV 발전량으로 냉방 및 전기기기의 전력 요 구량을 모두 충당하고도 상당량의 잉여전력이 생산되어 전량 판매하는 경우 Table 10 과 같이 전력 판매금액은 5,581 천원이고 난방요금 1,783 천원을 제하면 3,796 천원 의 이익이 발생한다. 반면 잉여전력을 난방에 추가로 사 용한 경우 Table 11 과 같이 12 월에만 난방요구량을 감당 하기 위해 가스사용이 필요하다. 잉여전력을 판매하여 총 3,690 천원의 수익이 발생하며 난방비용을 제하면 3,664 천원의 수익이 발생한다.
[Table 12] A summary of PV system economic analysis using air conditioning system

\begin{tabular}{|l|c|c|}
\hline & Case1 & Case2 \\
\hline $\begin{array}{l}\text { Installation Cost of PV } \\
\text { System }\end{array}$ & $23,947,000$ & $63,860,000$ \\
\hline $\begin{array}{l}\text { Installation Cost of Air } \\
\text { Conditioner }\end{array}$ & $1,500,000$ & $1,500,000$ \\
\hline $\begin{array}{l}\text { Annual Energy Cost } \\
\text { Saving (KRW) }\end{array}$ & $1,881,000$ & $5,796,000$ \\
\hline Break-Even Point (Year) & 13.5 & 11.3 \\
\hline PV System Life (Year) & \multicolumn{2}{|c|}{25} \\
\hline
\end{tabular}

[Table 13] A summary of PV system economic analysis using heat pump air conditioning system

\begin{tabular}{|l|c|c|}
\hline & Case1 & Case2 \\
\hline $\begin{array}{l}\text { Installation Cost of PV } \\
\text { System }\end{array}$ & $23,947,000$ & $63,860,000$ \\
\hline $\begin{array}{l}\text { Installation Cost of Heat } \\
\text { Pump Air Conditioner }\end{array}$ & $2,300,000$ & $2,300,000$ \\
\hline $\begin{array}{l}\text { Annual Energy Cost } \\
\text { Saving (KRW) }\end{array}$ & $1,810,000$ & $5,664,000$ \\
\hline Break-Even Point (Year) & 13.4 & 11.6 \\
\hline PV System Life (Year) & \multicolumn{2}{|c|}{25} \\
\hline
\end{tabular}

두 경우 모두 여유전력을 난방에 사용하는 경우 난방 에 사용하지 않는 경우와 비교해서 수익의 차이가 크지 않았다. 전력을 난방에 사용할 경우 냉난방기 설치비가 증가하기 때문에 큰 이점이 없는 것으로 판단되며 향후 $\mathrm{PV}$ 생산전력을 한전에 판매하는 가격과 가스가격이 변 동될 경우에는 최종 결과가 달라질 수 있음을 고려할 필 요가 있다.

$\mathrm{PV}$ 시스템이 없는 경우의 에너지 구매비용은 Table 6 과 7 로부터 총 2,000 천원으로 나타났다. PV 시스템을 적 용하여 경제성 분석을 한 결과는 Table 12,13 과 같으며 $\mathrm{PV}$ 시스템의 설치비용은 Case1 23,947천원, Case2 63,860 천원으로 계산되었다[13]. 발전된 전력의 냉난방 사용여부에 따라 냉방, 난방 설비에 따른 초기투자비용이 달라지며 Case1의 경우 냉난방에 전력을 사용하고 잉여 전력을 파는 것이 Case2의 경우 냉방에만 사용하고 전량 판매하는 것이 경제적으로 유리한 것으로 판단된다. Case2가 초기설치비용이 Case1의 약 2.5배에 달하지만 투자비용 회수기간 이후로는 약 3 배 더 많은 이익을 얻을 수 있으므로 수명연한인 25년 이상 사용 시 Case2가 경 제성 측면에서 유리할 것으로 판단된다.

\section{4. 결론}

본 연구에서는 EnergyPlus를 사용하여 농어촌 주택 표 
준모델 중 농림-10-33-다에 PV 시스템을 적용하여 연간 건물에너지요구량과 PV발전량을 계산하였다. PV 시스템 을 Case1, Case2로 나누어 지붕 위에 설치하고 발전량을 분석하였다.

(1) 건물에너지요구량을 계산한 결과 난방에너지요구 량은 $21.81 \mathrm{MWh}$, 냉방에너지요구량은 $3.18 \mathrm{MWh}$ 로 난방에너지요구량이 냉방에너지요구량보다 크 게 나타났다. 건물의 1 차 단위면적당 에너지소요량 은 약 $295.91 \mathrm{kWh}$ 로 에너지 효율 1등급 건물에 해 당한다.

(2) PV 시스템을 2가지 경우로 나누어 적용하고 발전량 을 분석하였다. PV 패널의 설치 면적이 증가함에 따라 발전량이 증가했으며 단위면적당 발전량은 Case1 $190.84 \mathrm{kWh} / \mathrm{m}^{2}$, Case2 $191.22 \mathrm{kWh} / \mathrm{m}^{2}$ 로 나타났다.

(3) Case1과 Case2에 적용된 PV 시스템의 경제성 분 석을 실시하였다. 초기투자비용은 Case1이 약 13년 차, Case2는 약 11년차가 지나면 회수되는 것으로 나타났다. Case2가 초기설치비용이 비싸지만 회수 기간이 짧고 회수기간이 지나면 Case1보다 약 3 배 더 많은 이익을 얻을 수 있어 수명연한인 25년 이상 사용 시 경제성 측면에서 유리할 것으로 판단된다.

\section{References}

[1] Y. S. Song and D. Y. Hwang, "Current Status and Future Directions of Return to Farming Education", The Society of Korea Agricultural Education 2010 Annual Conference, pp. 95-121, 2010.

[2] Korea Rural Community Corporation, "Standard Rural House Model", www.welchon.or.kr

[3] J. H. Yoon, J. S. Park, and K. I. Jin, "A Study on the Power Saving Fraction of Site Electrical Load depending on the Installation Area of PV system in Apartment Complex", Journal of the Korean Solar Energy Society, Vol. 28, No. 3, pp. 60-66, 2008.

[4] S. H. Lee, H. S. Park, and B. Y. Lee, "A Study on Analysis of Energy Consumption of Detached House by U-value and SCs of Windows and Building Orientation", Journal of the Korean Solar Energy Society, Vol. 32, No. 3, pp. 96-103, 2012. DOI: http://dx.doi.org/10.7836/kses.2012.32.3.096

[5] K. I. Chin, J. H. Yoon, and H. J. Kim, "Window PV System Design for Apartment Balcony and Evaluation of Energy Output", Korean Institute of Architectural Sustainable Environment and Building Systems Spring
Conference, pp. 217-220, 2010.

[6] O. E. Kwon, H. R. Kim, G. H. Kang, G. J. Yu, K. S. Kim, and J. S. Kim, "A Study on the Performance of BIPV System using Simulation", The Korean Solar Energy Society 2011 Spring Annual Conference, Vol. 30, No. 2, pp. 9-14, 2010.

[7] J. H. Yoon, W. C. Shin, and J. W. Park, "Software Development on Power and Economic Analysis of Photovoltaic System fo Building Application", Journal of the Korean Solar Energy Society, Vol. 28, No. 1, pp. $1-8,2008$.

[8] C. K. Lee and W. T. Kim, "Heating and Cooling Energy Demand Analysis of Standard Rural House Models", Journal of the Korea Academia-Industrial cooperation Society, Vol. 13, No. 8, 2012, in press.

[9] U.S. Department of Energy, "EnergyPlus Engineering Reference - The Reference to EnergyPlus Calculation", 2010.

[10] ASHRAE, "ASHRAE Handbook -Fundamentals, Chapter 28, Climate Design Information”, pp. 28.1-28.10, 2005.

[11] Korea Energy Management Corporation, "Guidelines for the Indoor Temperature to Save Electricity in Summertime", www.kemco.or.kr

[12] Korea Energy Management Corporation, "Regulations for Building Energy Efficiency Rating and Certification”, pp. 32700.1-32700.20, 2007.

[13] LG Electronics, "Manual for High Efficiency Single Crystal PV Module", www.solar.lge.co.kr

[14] S. H. Park and J. H. Seo, "A Study on the Optimum Selection of Placing Photovoltaic Module in the Metropolitan City Using a TRNSYS", The Korean Solar Energy Society Autumn Annual Conference, Vol. 31, No. 2, pp. 297-302, 2011.

이 찬 규(Chan-Kyu Lee)

[준회원]

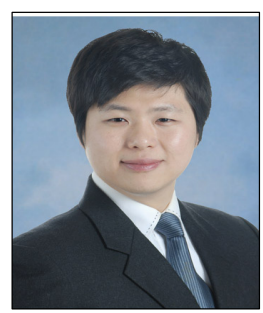

- 2011년 2월 : 공주대학교 기계자 동차공학부 자동차공학전공(학사)

- 2013년 2월 : 공주대학교 기계공 학과 (석사)

- 2013년 2월 현재 : 한국에너 지기술연구원 에너지효율연구단 연구원

<관심분야>

에너지공학, 자동차공학, 열유체공학 
김 우 태(Woo-Tae Kim)

[정회원]

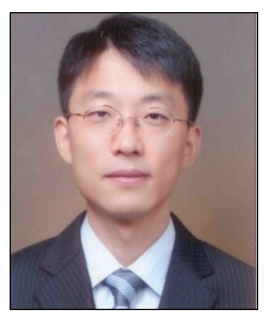

- 2000년 8월 : 포항공과대학교 기 계공학과 (공학박사)

- 2001년 11월 2002년 10월 : 워털루대학교 기계공학과

- 2002년 12월 2005년 9월 : 카 네기멜론대학교 Data Storage Systems Center

- 2005년 10월 2009년 8월 : 삼 성코닝정밀소재 기술연구소

- 2009년 9월 현재 : 공주대학교 기계자동차공학부 조 교수

<관심분야>

열유체공학, 에너지공학, 전산유체역학, 연소공학 